\title{
Lifetime socioeconomic position in relation to onset of perimenopause
}

\author{
L A Wise, N Krieger, S Zierler, B L Harlow
}

J Epidemiol Community Health 2002;56:851-860

See end of article for authors' affiliations .....................

Correspondence to: Ms L A Wise, Slone Epidemiology Center 1010 Commonwealth Avenue, 4th floor, Boston, MA, 02215, USA: Iwise@hsph.harvard.edu.

Accepted for publication 19 March 2002

\begin{abstract}
Study objective: To assess the association between lifetime socioeconomic position and onset of perimenopause.

Design: Prospective cohort study.

Setting: Boston, Massachusetts.

Participants: 603 premenopausal women aged 36-45 years at baseline who completed a cross sectional survey on childhood and adult socioeconomic position.

Main outcome measures: Time to perimenopause, defined as time in months from baseline interview to a woman's report of (1) an absolute change of at least seven days in menstrual cycle length from baseline or subjective report of menstrual irregularity; (2) a change in menstrual flow amount or duration; or (3) cessation of periods for at least three months, whichever came first.

Main results: Incidence of perimenopause was 1.75 times higher $(95 \% \mathrm{Cl} 1.10$ to 2.79$)$ and median age at onset was 1.2 years younger (44.7 v 45.9 years) for women reporting childhood and adult economic distress compared with women reporting no lifetime economic distress. After adjustment for age, race/ethnicity, age at menarche, parity, oral contraceptive use, family history of early menopause, depression, smoking, and body mass index, the association weakened (incidence rate ratio (IRR) $=1.59 ; 95 \% \mathrm{Cl} 0.97$ to 2.61 ). Inverse associations were observed for most, but not all, measures of educational level. Measures of current household income were not associated with risk of perimenopause.

Conclusions: This study suggests that adverse socioeconomic conditions across the lifespan, when measured in terms of economic hardship and low educational attainment, may be associated with an increased rate of entry into perimenopause.

woman's age at entry into perimenopause depends on her initial number of oocytes and the rate at which they are depleted. ${ }^{12}{ }^{17} 18$ We hypothesised that adverse socioeconomic conditions across the life span may lead to an earlier age at onset of perimenopause by influencing such factors as initial germ cell quantity, rate of oocyte depletion, or quality of a woman's remaining oocytes. To test the hypothesis that low lifetime socioeconomic position is associated with early incidence of perimenopause, we examined their relation in a prospective cohort study of women of late reproductive age from Boston, Massachusetts.

\section{METHODS}

The Harvard Study of Moods and Cycles is a prospective cohort study designed primarily to assess the association between major depression and ovarian function among women of late reproductive age. From 1995 to 1997, a random sample of 6228 women aged 36 to 45 years residing in seven Boston area communities was selected from Massachusetts Town Books, using a table of random numbers. Respondents were mailed an initial questionnaire to assess menopausal status and depressive symptoms using the Center for Epidemiologic Studies Depression scale (CES-D). ${ }^{19}$ Of the 4569 (73.5\%) women who completed the CES-D screener, those who scored high $(\geqslant 25)$ on the CES-D or who indicated a history of depression that lead to psychotherapy or pharmacotherapy were eligible for enrollment into the depressed cohort $(n=1187)$. Women who scored low $(<16)$ on the CES-D and did not report any history of depression were eligible for selection into the non-depressed cohort $(n=1908)$. We further assessed the presence of major depressive disorder using the Structured Clinical Interview for DSM-IV disorders (SCID), a semistructured diagnostic schedule. ${ }^{20}$ The final study population
\end{abstract}

W hile childhood and adult socioeconomic position are increasingly recognised as important determinants of cardiovascular disease and all cause mortality, ${ }^{1}$ their influence on ovarian function is less clear. Existing research has yielded inconsistent findings on the relation between adult social class and the menopausal transition (perimenopause). Several studies have reported an independent association between early age at natural menopause and low adult socioeconomic position, as measured by educational attainment, ${ }^{2-5}$ income, ${ }^{3}$ and occupation, ${ }^{4}$ even after adjustment for current smoking ${ }^{2-5}$ or ever smoking. ${ }^{3}$ However, other studies have shown no independent effect of adult socioeconomic position measures on either age at menopause ${ }^{6-8}$ or age at perimenopause. ${ }^{9}$ Only two of these studies have investigated the contribution of childhood and/or cumulative lifetime socioeconomic position on risk of early ovarian decline. ${ }^{79}$ Studies have also varied in their treatment of risk factors for early age at perimenopause as either confounders or variables in the causal pathway, such as cigarette smoking, ${ }^{2}{ }^{9-11}$ body mass index (BMI), ${ }^{911}$ early menarche, ${ }^{12}$ nulliparity, ${ }^{12}$ non-use of oral contraceptives, ${ }^{312}$ being a woman of colour, ${ }^{8}$ and oophorectomy. ${ }^{13}$ As current smoking and BMI are potential intermediates of the causal pathway under study, careful consideration should be taken before controlling for these factors, especially if they explain, in part, how socioeconomic position may influence a decline in ovarian function.

Understanding the social determinants of premature decline in ovarian function has important implications for women's health. Early menopause is associated with an increased risk of cardiovascular morbidity and mortality, ${ }^{14}$ osteoporosis, ${ }^{15}$ and thyroid disorders. ${ }^{16}$ One prevailing theory is that the timing of menopause is directly related to the depletion of oocyte quantity to a critical threshold, such that a 
comprised 332 women with a history of depression and 644 women without such a history $(n=976)$. Further details pertaining to the enrollment of women in the Harvard Study of Moods and Cycles may be found elsewhere. ${ }^{21}$

Starting at baseline (1996-1997), and every six months over the 36 month follow up period, we elicited information on demographic, reproductive, psychiatric, and general health characteristics. Trained lay interviewers administered all in-person interviews. In addition to the main study protocol, investigators from Brown University, Harvard School of Public Health, and the Brigham and Women's Hospital, designed a self administered postal survey to investigate social determinants of accelerated ovarian aging. In March 1999, on average 18 months after initial study enrollment, we mailed the survey to 907 active members of the Harvard Study of Moods and Cycles. A total of $733(81 \%)$ returned the survey with usable information. At the time of the survey mailing, 69 of the 976 members of the main cohort study were lost to follow up ( $5.4 \%$ non-depressed $v 8.1 \%$ depressed). Comparable response was obtained for depressed (80\%) and non-depressed $(81.6 \%)$ women. Research was approved by the Human Subjects Committees at each of the collaborating centres listed above.

\section{Assessment of socioeconomic position}

The self administered "Survey of Interpersonal Relationships" was designed to measure lifetime socioeconomic position in relation to material deprivation, wealth, social class position, and educational assets across four different time periods: ( 1 ) childhood, (2) adolescence, (3) adulthood, and (4) in the past year. Derived in part from the sociocultural module of the US Department of Health and Human Services Breast Cancer Core Questionnaire, ${ }^{22-25}$ socioeconomic variables were designed to capture unmet economic need, usual occupational class of main wage earner in household (business owner with five or more employees, business owner with less than five employees, supervisory employee, non-supervisory employee, or unemployed), educational credentials over the lifecourse, race/ethnicity (self identified), and sexual identity.

Our main variable of interest was "economic distress," defined by self report of any of the following in a given time period: (a) receipt of public assistance or welfare $(n=65)$; (b) inability to pay for food, rent, or mortgage $(n=121)$; (c) not having enough money to "make ends meet" $(n=174)$, or $(d)$ borrowing money to pay for medical expenses $(n=59)$. Among women reporting any lifetime economic distress $(n=203)$, $31 \%$ reported at least three definitional criteria and $70 \%$ reported at least two definitional criteria. A priori, we hypothesised that these events would be better able to discriminate between those with and without unmet economic need across the life span. Given that we could not feasibly ask participants to recall their parents' income, we believed that events captured by the "economic distress" construct would be easier to recall and more reliably reported than traditional variables such as parents' income, education, or occupation. The literature also shows good correlation between the above measures of economic distress. ${ }^{23}$

All time periods of economic distress - childhood (including adolescence), adulthood (including "in the past year"), or both childhood and adulthood-were compared with a reference group of women reporting no economic distress across the life span. Current household poverty level was defined as percentage income above or below the US poverty line and was calculated using information on yearly household income, family size, and number and age of dependants, according to the US census data poverty matrix from $1998 .{ }^{26}$ In addition, we assessed current financial stability by inquiring about additional income from assets (that is, interest from a bank account, dividends from stocks or bonds, and rent from property owned) and by asking respondents "if you suddenly lost all sources of household income right now, how long would you be able to maintain your standard of living?"

\section{Assessment of perimenopause}

Our main outcome of interest was inception of perimenopause as a marker of early ovarian decline. The World Health Organisation (WHO) defines perimenopause as the time immediately preceding the menopause beginning with endocrine, biological, and clinical changes and ending a year after the final menstrual period. ${ }^{16}{ }^{27}$ During this phase, the rate of ovarian follicle depletion increases as the ovaries lose their ability to undergo ovulation and produce oestrogen and progesterone. Often, the first sign of perimenopause is menstrual irregularity, resulting from erratic ovarian hormone secretion and decreased frequency of ovulation. In the early phase of perimenopause, women may experience shortening of their menstrual cycles by two to seven days, increased quantity of menstrual flow, and mid-cycle spotting. Later in perimenopause, skipped periods or longer cycles are common, as fewer follicles remain and anovulation occurs. Up to $90 \%$ of women may experience the onset of changes in menstrual patterns, beginning as early as age $36 .{ }^{28-30}$ In studies by Treloar, ${ }^{29}{ }^{30}$ the average age for entry into perimenopause was 45.1, with a mean duration of five years (range two to eight years). Median age at inception of perimenopause has been estimated at $47-48$ years. $^{12} 13$

Every six months over the 36 month follow up period, we collected detailed data on current menstrual cycle length (the usual number of days from the start of one menses to the start of another), days of menstrual flow, amount of menstrual flow (light, moderate, moderately heavy, heavy), and cycle regularity ("are your cycles now generally regular, that is usually predictable within 10 days?"). A complete record of hormone use was collected, including reason for use: (a) contraception, (b) fertility therapy, or (c) menstrual regulation/hormone replacement therapy (HRT). We also inquired about reproductive surgeries (hysterectomy or oophorectomy) and cessation of periods for any reason, including pregnancy, lactation, hormone use, or menopause (natural, surgical, or medical).

Informed by the Massachusetts Women's Health Study, ${ }^{61}{ }^{32}$ the Seattle Midlife Women's Health Study, ${ }^{28}$ and related epidemiological research, ${ }^{92}{ }^{33}$ we defined time of entry into perimenopause as time, in months, from the baseline interview to the follow up interview in which a woman reported the occurrence of any of the following events within the previous six months: (1) subjective report of menstrual irregularity or an absolute change of seven days or greater in menstrual cycle length as compared with baseline; (2) a change in menstrual flow amount $(\geqslant 2$ flow categories, for example, from light to moderately heavy) or duration (absolute change of $\geqslant 2$ days); or (3) periods of amenorrhea lasting at least three months.

\section{Exclusionary criteria}

Of the 733 women who completed our survey, we excluded women who, at the time of their baseline interview, reported never having regular cycles throughout their lifetime $(n=8)$ or current experience of menstrual irregularity, characterised by cycle unpredictability or amenorrhea $(n=62)$. We further excluded women using hormones at baseline $(n=60)$ as a change in menstrual cycle characteristics from baseline could not be validly assessed. Overall, women excluded from the analysis were more likely to be younger, nulliparous, report more years of oral contraceptive use, have a lower BMI, and have more than four years college education than those included in the final analysis. Those included in the study did not differ appreciably from those excluded with respect to other socioeconomic position variables, smoking status, race/ethnicity, or a history of depression. Our final analytical sample comprised 603 women.

Assessment of other covariates

Additional data on covariates were obtained from the baseline questionnaire, including age, age at menarche, smoking 
Table 1 Sociodemographic and reproductive characteristics measured at baseline, overall and stratified by lifetime economic distress, among 603 women aged 36-45 years from the Harvard Study of Moods and Cycles, Boston, Massachusetts, 1996-2000

\begin{tabular}{|c|c|c|c|c|c|}
\hline & \multirow[b]{2}{*}{$\begin{array}{l}\text { Total } \\
(n=603)\end{array}$} & \multicolumn{4}{|c|}{ Lifetime economic distress* } \\
\hline & & $\begin{array}{l}\text { No lifetime } \\
\text { economic distress } \\
(\mathrm{n}=400)\end{array}$ & $\begin{array}{l}\text { Economic distress } \\
\text { as child only } \\
(\mathrm{n}=73)\end{array}$ & $\begin{array}{l}\text { Economic distress } \\
\text { as adult only } \\
(\mathrm{n}=84)\end{array}$ & $\begin{array}{l}\text { Economic distress } \\
\text { as child and adul } \\
(n=46)\end{array}$ \\
\hline \multicolumn{6}{|l|}{ Age at baseline $(y), n(\%)$} \\
\hline $36-37$ & $90(14.9)$ & $62(15.5)$ & $11(15.1)$ & $11(13.1)$ & $6(13.0)$ \\
\hline $38-39$ & $162(26.9)$ & $108(27.0)$ & $22(30.1)$ & $19(22.6)$ & $13(28.3)$ \\
\hline $40-41$ & $137(22.7)$ & $96(24.0)$ & 14 (19.2) & 15 (17.9) & $12(26.1)$ \\
\hline $42-43$ & $153(25.4)$ & 93 (23.2) & $22(30.1)$ & 28 (33.3) & $10(21.7)$ \\
\hline $44-45$ & $61(10.1)$ & $41(10.3)$ & $4(5.5)$ & $11(13.1)$ & $5(10.9)$ \\
\hline \multicolumn{6}{|l|}{ Age at menarche $(y), n(\%)$} \\
\hline$<12$ & $99(16.4)$ & $62(15.5)$ & $10(13.7)$ & $16(19.1)$ & $11(23.9)$ \\
\hline $12-14$ & $438(72.6)$ & $296(74.0)$ & 55 (75.3) & 60 (71.4) & $27(58.7)$ \\
\hline$>14$ & $66(11.0)$ & $42(10.5)$ & $8(11.0)$ & $8(9.5)$ & $8(17.4)$ \\
\hline \multicolumn{6}{|l|}{ Oral contraceptive use (y), $n(\%)$} \\
\hline Never use & $183(30.4)$ & $123(30.8)$ & $23(31.5)$ & $26(30.9)$ & $11(23.9)$ \\
\hline $1-5$ & $295(48.9)$ & $196(49.0)$ & $32(43.9)$ & $42(50.0)$ & 25 (54.4) \\
\hline $6-11$ & 85 (14.1) & $50(12.5)$ & $16(21.9)$ & $13(15.5)$ & $6(13.0)$ \\
\hline$>11$ & $40(6.6)$ & $31(7.7)$ & $2(2.7)$ & $3(3.6)$ & $4(8.7)$ \\
\hline \multicolumn{6}{|l|}{ Parity, n (\%) } \\
\hline Nulliparous & 206 (34.2) & $140(35.0)$ & 25 (34.2) & $28(33.3)$ & $13(28.3)$ \\
\hline 1-2 livebirths & $284(47.1)$ & $184(46.0)$ & $37(50.7)$ & $37(44.1)$ & $26(56.5)$ \\
\hline$\geqslant 3$ livebirths & $113(18.7)$ & $76(19.0)$ & 11 (15.1) & $19(22.6)$ & $7(15.2)$ \\
\hline \multicolumn{6}{|l|}{ Race/ethnicity, n(\%)† } \\
\hline White, non-Hispanic women & $570(94.5)$ & $382(95.5)$ & $69(94.5)$ & $76(90.5)$ & $43(93.5)$ \\
\hline Women of colour, including Hispanic & $33(5.5)$ & $18(4.5)$ & $4(5.5)$ & $8(9.5)$ & $3(6.5)$ \\
\hline Family history of early menopause, $n(\%) \ddagger$ & $46(7.6)$ & $29(7.3)$ & $10(13.7)$ & $3(3.6)$ & $3(8.7)$ \\
\hline \multirow{2}{*}{\multicolumn{6}{|c|}{ Depression at baseline, $\mathrm{n}(\%)$}} \\
\hline & & & & & \\
\hline Never & $409(67.8)$ & $284(71.0)$ & $57(78.1)$ & $46(54.8)$ & $22(47.8)$ \\
\hline Past or current & $194(32.2)$ & $116(29.0)$ & $16(21.9)$ & $38(45.2)$ & $22(52.2)$ \\
\hline \multicolumn{6}{|l|}{ Body mass index $\left(\mathrm{kg} / \mathrm{m}^{2}\right), \mathrm{n}(\%)$} \\
\hline$<20$ & $83(13.7)$ & $66(16.5)$ & $6(8.2)$ & $7(8.3)$ & $4(8.7)$ \\
\hline $20-24$ & $332(55.1)$ & $228(57.0)$ & $38(52.1)$ & $46(54.8)$ & $20(43.5)$ \\
\hline $25-29$ & $120(19.9)$ & $72(18.0)$ & $13(17.8)$ & $21(25.0)$ & $14(30.4)$ \\
\hline $30+$ & $68(11.3)$ & $34(8.5)$ & $16(21.9)$ & 10 (11.9) & $8(17.4)$ \\
\hline \multicolumn{6}{|l|}{ Smoking status, $\mathrm{n}(\%)$} \\
\hline Never & $330(54.7)$ & $233(58.3)$ & $38(52.0)$ & $35(41.7)$ & $24(52.2)$ \\
\hline Past & $212(35.2)$ & $130(32.5)$ & $31(42.5)$ & $37(44.0)$ & $14(30.4)$ \\
\hline Current & $61(10.1)$ & $37(9.2)$ & $4(5.5)$ & $12(14.3)$ & $8(17.4)$ \\
\hline \multicolumn{6}{|l|}{ Marital status, n (\%) } \\
\hline \multicolumn{6}{|l|}{ Ever married or partnered } \\
\hline No history divorce, separation, widowhood & $384(63.7)$ & $275(68.8)$ & $45(61.6)$ & $44(52.4)$ & $20(43.5)$ \\
\hline History divorce, separation or widowhood & $127(21.1)$ & $64(16.0)$ & $17(23.3)$ & $26(30.9)$ & $20(43.5)$ \\
\hline Never married or partnered & $92(15.2)$ & $61(15.2)$ & $11(15.1)$ & 14 (16.7) & $6(13.0)$ \\
\hline \multicolumn{6}{|l|}{ Sexual Identity, n (\%) } \\
\hline Heterosexual & $537(89.0)$ & $359(89.7)$ & $69(94.5)$ & $67(79.8)$ & $42(91.3)$ \\
\hline Gay, lesbian, or bisexual & $66(11.0)$ & $41(10.3)$ & $4(5.5)$ & $17(20.2)$ & $4(8.7)$ \\
\hline
\end{tabular}

*Defined as self report of any of following in given time period: (a) receipt of public assistance or welfare; (b) inability to pay for food, rent, or mortgage; (c) not being able to "make ends meet"; or (d) having to borrow money to cover medical expenses. †Women of colour: Hispanic: $3=$ white, $3=$ not specified; Not Hispanic: 9=black, 7=Chinese, 2=Japanese, 1=Asian Indian, 4=Native American, 4=not specified. $\neq$ Defined as having a mother or sister with natural menopause before age 46 years.

(never, past, current), years of oral contraceptive use, family history of early menopause (defined as having a mother or sister with natural menopause before age 46 years), parity, BMI $\left(\mathrm{kg} / \mathrm{m}^{2}\right)$ classified according to WHO guidelines $(<20$, 20-24, 25-29, and 30+ ), ${ }^{34}$ marital status, unilateral oophorectomy (defined as removal of all or part of one ovary), history of DSM-IV defined major depression, and years of living with a smoker.

\section{Data analysis}

Our analytic goal was to estimate the incidence of perimenopause in relation to childhood and adult socioeconomic position. All women were considered "at risk" for perimenopause until the occurrence of a perimenopausal event, a censoring event, or the end of the 36 month study period. Women were censored at the end of the follow up interval in which they reported pregnancy $(n=42)$; hysterectomy, bilateral oophorectomy, or medical menopause $(\mathrm{n}=5)$; or initiation of hormone use $(n=64 ; n=20$ for contraception, $n=11$ for fertility therapy, and $n=33$ for HRT). Women who started hormone use and reported perimenopausal events in the same time interval were censored because we could not determine whether it was the hormone use that caused a change in cycle regularity or vice versa. Women who were lost to follow up $(n=59)$ or who remained premenopausal at the end of follow up $(n=256)$ were also censored.

We first examined the distribution of the outcome variable among all women, stratified by selected baseline characteristics and indicators of socioeconomic position. We then used Kaplan-Meier product limit survival analysis ${ }^{35}$ to estimate the median time to perimenopause (in months) and to make univariate comparisons of discrete groups of women. Log rank test ${ }^{36}$ were performed as a statistical evaluation for the equality of survival curves and their median values.

Cox proportional hazards regression models were used to derive estimates of the incidence rate ratio (IRR) and 95\% confidence intervals (CI) for the relation between socioeconomic position and time to inception of perimenopause, while 


\begin{tabular}{|c|c|c|c|c|c|}
\hline Demographic and reproductive characteristics & Total & $\begin{array}{l}\text { Number of } \\
\text { women reaching } \\
\text { perimenopause }\end{array}$ & $\begin{array}{l}\text { Woman years } \\
\text { of follow up }\end{array}$ & $\begin{array}{l}\text { Crude IR } \\
\text { (cases/1000 } \\
\text { woman years) }\end{array}$ & $\begin{array}{l}\text { Age adjusted IRR } \dagger \\
(95 \% \mathrm{Cl})\end{array}$ \\
\hline \multicolumn{6}{|l|}{ Age at baseline (y) } \\
\hline $36-37$ & 90 & 19 & 192 & 99 & 1.00 \\
\hline $38-39$ & 162 & 34 & 352 & 97 & $0.97(0.55$ to 1.70$)$ \\
\hline $40-41$ & 137 & 45 & 294 & 153 & 1.54 (0.90 to 2.54$)$ \\
\hline $42-43$ & 153 & 53 & 319 & 166 & 1.68 (0.99 to 2.84$)$ \\
\hline $44-45$ & 61 & 26 & 119 & 218 & $\begin{array}{l}2.25 \text { (1.24 to } 4.06) \\
\text { p for trend: }<0.001\end{array}$ \\
\hline \multicolumn{6}{|l|}{ Age at menarche (y) } \\
\hline$<12$ & 99 & 26 & 216 & 121 & 1.00 \\
\hline $12-14$ & 438 & 130 & 929 & 140 & 1.18 (0.77 to 1.79 ) \\
\hline$>14$ & 66 & 21 & 131 & 160 & 1.50 (0.84 to 2.68$)$ \\
\hline \multicolumn{6}{|l|}{ Parity } \\
\hline Núlliparous & 206 & 54 & 439 & 123 & 1.00 \\
\hline 1-2 livebirths & 284 & 85 & 598 & 142 & $1.07(0.76$ to 1.52$)$ \\
\hline$\geqslant 3$ livebirths & 113 & 38 & 238 & 159 & $1.23(0.81$ to 1.88$)$ \\
\hline \multicolumn{6}{|l|}{ Oral contraceptive use } \\
\hline Never use & 183 & 53 & 390 & 136 & 1.00 \\
\hline $1-5$ years & 295 & 90 & 624 & 144 & 0.95 (0.67 to 1.35 ) \\
\hline $6-11$ years & 85 & 19 & 184 & 103 & 0.72 (0.43 to 1.23 ) \\
\hline$>11$ years & 40 & 15 & 78 & 192 & $1.34(0.75$ to 2.40$)$ \\
\hline \multicolumn{6}{|l|}{ Race/ethnicity* } \\
\hline White, non-Hispanic women & 570 & 159 & 1217 & 131 & 1.00 \\
\hline Women of colour, including Hispanic & 33 & 18 & 59 & 305 & 2.36 (1.44 to 3.89 ) \\
\hline \multicolumn{6}{|l|}{ DSM-IV defined depression at baseline } \\
\hline Never & 409 & 111 & 880 & 126 & 1.00 \\
\hline Past or current & 194 & 66 & 396 & 167 & $1.28(0.94$ to 1.74$)$ \\
\hline \multicolumn{6}{|l|}{ Body mass index $\left(\mathrm{kg} / \mathrm{m}^{2}\right)$} \\
\hline$<20$ & 83 & 23 & 177 & 130 & $1.04(0.66$ to 1.65$)$ \\
\hline $20-24$ & 332 & 91 & 711 & 128 & 1.00 \\
\hline $25-29$ & 120 & 35 & 252 & 139 & $1.05(0.71$ to 1.55$)$ \\
\hline $30+$ & 68 & 28 & 136 & 206 & 1.58 (1.03 to 2.43$)$ \\
\hline \multicolumn{6}{|l|}{ Family history of early natural menopause $\ddagger$} \\
\hline No & 557 & 155 & 1194 & 130 & 1.00 \\
\hline Yes & 46 & 22 & 82 & 268 & 2.10 (1.32 to 3.34$)$ \\
\hline \multicolumn{6}{|l|}{ Removal of all or part of ovary } \\
\hline No & 583 & 170 & 1239 & 137 & 1.00 \\
\hline Yes & 20 & 7 & 37 & 189 & $1.39(0.65$ to 2.98$)$ \\
\hline \multicolumn{6}{|l|}{ Smoking status } \\
\hline Never & 330 & 100 & 691 & 145 & 1.00 \\
\hline Past & 212 & 54 & 447 & 121 & $0.81(0.58$ to 1.12$)$ \\
\hline Current & 61 & 23 & 138 & 167 & 1.24 (0.78 to 1.99$)$ \\
\hline \multicolumn{6}{|l|}{ Number of years lived with smoker in home $(n=562)$} \\
\hline$<5$ & 400 & 103 & 863 & 119 & 1.00 \\
\hline $5-15$ & 116 & 41 & 233 & 176 & $1.41(0.98$ to 2.03$)$ \\
\hline$>15$ & 46 & 19 & 97 & 196 & $1.49(0.90$ to 2.45$)$ \\
\hline \multicolumn{6}{|l|}{ History of divorce, separation, widowhood } \\
\hline \multicolumn{6}{|l|}{ Ever married or partnered } \\
\hline No history divorce, separation, widowhood & 384 & 108 & 819 & 132 & 1.00 \\
\hline History divorce, separation or widowhood & 127 & 39 & 257 & 152 & $1.20(0.80$ to 1.81$)$ \\
\hline Never married or partnered & 92 & 30 & 200 & 150 & 1.05 (0.73 to 1.52$)$ \\
\hline \multicolumn{6}{|l|}{ Sexual identity } \\
\hline Heterosexual & 537 & 159 & 1131 & 141 & 1.00 \\
\hline Gay, lesbian, or bisexual & 66 & 18 & 145 & 124 & $0.98(0.60$ to 1.62$)$ \\
\hline
\end{tabular}

adjusting for potential confounders. ${ }^{37}$ The hazard function for each variable was related to the conditional probability of reaching perimenopause at time $t$, given that a woman had not reached perimenopause up to time $t$. Women with incomplete information for any of the variables in our study were left as missing. ${ }^{38}$ We used the PHREG procedure in SAS (version $8.0),{ }^{39}$ with the "exact" option to handle a high proportion of tied event times as a result of imprecise outcome measurement. ${ }^{40}$

Our choice of covariates for model selection was guided by external knowledge regarding the association between socioeconomic position and perimenopause. Our final multivariate model included: age at baseline (continuous), parity (nulliparous, $1-2$ livebirths, $\geqslant 3$ livebirths $)$, age at menarche $(<12$,
$12-14,>14$ years), years of oral contraceptive use (never use, $1-5,6-10$, and 11 or more years), and family history of early natural menopause. We created a separate model to further control for race/ethnicity, history of depression, smoking (never, past, current), and BMI, the latter two of which are potential intermediary variables. We believed the control for race/ethnicity, conceptualised as a social variable, would not only capture unmeasured aspects of socioeconomic position but also the impact of racial discrimination on ovarian function, if any. ${ }^{23}$ Covariates shown to be linear on the log hazard scale with respect to outcome (for example, age) were modelled as continuous variables. The assumption of proportional hazards was evaluated for the final model by plotting 
Table 3 Crude incidence rates along with crude and adjusted incidence rate ratios (IRRs) for time to perimenopause, stratified by socioeconomic characteristics, among 603 women from the Harvard Study of Moods and Cycles, Boston, Massachusetts, 1996-2000

\begin{tabular}{|c|c|c|c|c|c|}
\hline Socioeconomic position variables & Total & $\begin{array}{l}\text { Crude IR } \\
\text { (cases/1000 } \\
\text { woman years) }\end{array}$ & $\begin{array}{l}\text { Crude IRR } \\
(95 \% \mathrm{CI})\end{array}$ & $\begin{array}{l}\text { Adjusted IRR* } \\
\text { (95\% CI) }\end{array}$ & $\begin{array}{l}\text { Adjusted IRR* } † \\
(95 \% \mathrm{Cl})\end{array}$ \\
\hline \multicolumn{6}{|l|}{ Economic distress across lifecourse: } \\
\hline Never & 400 & 127 & 1.00 & 1.00 & 1.00 \\
\hline As child but not adult & 73 & 148 & $1.15(0.73$ to 1.81$)$ & $1.11(0.69$ to 1.76$)$ & $1.10(0.69$ to 1.80$)$ \\
\hline As adult but not child & 84 & 144 & $1.12(0.73$ to 1.72$)$ & $1.14(0.74$ to 1.75$)$ & $1.03(0.66$ to 1.60$)$ \\
\hline As both child and adult & 46 & 221 & $1.75(1.10$ to 2.79$)$ & $1.80(1.12$ to 2.89$)$ & $1.59(0.97$ to 2.61$)$ \\
\hline \multicolumn{6}{|c|}{ If lost sources of household income, could maintain current standard of living for: ( $n=601$ ) } \\
\hline More than 2 months & 427 & 132 & 1.00 & 1.00 & 1.00 \\
\hline Less than 2 months & 95 & 154 & $1.19(0.80$ to 1.76$)$ & $1.28(0.86$ to 1.90$)$ & $1.13(0.75$ to 1.69$)$ \\
\hline Don't know & 79 & 162 & $1.23(0.80$ to 1.88$)$ & $1.21(0.79$ to 1.86$)$ & $1.09(0.71$ to 1.70$)$ \\
\hline \multicolumn{6}{|l|}{ Current adult household income: } \\
\hline \multicolumn{6}{|l|}{ Percentage of poverty line, US census $\ddagger(n=590)$} \\
\hline$>400$ & 245 & 142 & 1.00 & 1.00 & 1.00 \\
\hline $200 \%-400$ & 267 & 128 & $0.91(0.66$ to 1.26$)$ & $0.91 \quad(0.65$ to 1.25$)$ & $0.85(0.61$ to 1.19$)$ \\
\hline$<200$ & 78 & 157 & $1.11(0.70$ to 1.74$)$ & $1.07(0.67$ to 1.70$)$ & $0.90(0.55$ to 1.44$)$ \\
\hline \multicolumn{6}{|l|}{ Current income from assets: } \\
\hline $\begin{array}{l}\text { Bank account interest, rent from owned property, or } \\
\text { dividends from stocks or bonds }\end{array}$ & 331 & 138 & 1.00 & 1.00 & 1.00 \\
\hline Bank account interest only, no rent or dividends & 87 & 133 & $0.97(0.62$ to 1.50$)$ & $1.10(0.70$ to 1.72$)$ & $1.12(0.71$ to 1.76$)$ \\
\hline No income from assets & 185 & 143 & $1.03(0.74$ to 1.44$)$ & $1.10(0.79$ to 1.53$)$ & $0.94(0.66$ to 1.33$)$ \\
\hline \multicolumn{6}{|l|}{ Highest level of education, respondent } \\
\hline Graduate degree & 260 & 127 & 1.00 & 1.00 & 1.00 \\
\hline College degree & 194 & 143 & $1.13(0.80$ to 1.60$)$ & $1.16(0.82$ to 1.64$)$ & $1.16(0.82$ to 1.66$)$ \\
\hline Some college, vocational, technical & 118 & 139 & $1.11(0.74$ to 1.66$)$ & $1.09(0.72$ to 1.65$)$ & $0.99(0.64$ to 1.52$)$ \\
\hline High School diploma & 31 & 206 & $1.66(0.92$ to 3.00$)$ & $1.51 \quad(0.82$ to 2.76$)$ & $1.24(0.65$ to 2.38$)$ \\
\hline \multicolumn{6}{|l|}{ Highest level of education, childhood household $(n=590) \S$} \\
\hline Graduate or college degree & 306 & 133 & 1.00 & 1.00 & 1.00 \\
\hline Some college, vocational, technical & 106 & 136 & $1.02(0.67$ to 1.55$)$ & $1.02(0.67$ to 1.55$)$ & $1.01(0.66$ to 1.55$)$ \\
\hline High School diploma & 150 & 129 & $0.98(0.68$ to 1.41$)$ & $0.87(0.60$ to 1.26$)$ & $0.84(0.58$ to 1.22$)$ \\
\hline Less than 12 th grade & 28 & 231 & $1.78(0.97$ to 3.27$)$ & $1.80(0.96$ to 3.35$)$ & $1.50(0.79$ to 2.85$)$ \\
\hline \multicolumn{6}{|l|}{ Highest level of education, current adult household } \\
\hline Graduate degree & 347 & 123 & 1.00 & 1.00 & 1.00 \\
\hline College degree & 156 & 154 & $1.26(0.90$ to 1.77$)$ & $1.36(0.96$ to 1.93$)$ & $1.37(0.96$ to 1.96$)$ \\
\hline Some college, vocational, technical & 85 & 152 & $1.26(0.83$ to 1.93$)$ & $1.26(0.82$ to 1.94$)$ & $1.14(0.73$ to 1.79$)$ \\
\hline High school diploma & 15 & 269 & 2.24 (1.04 to 4.83$)$ & $2.07(0.94$ to 4.54$)$ & $1.73(0.75$ to 3.98$)$ \\
\hline \multicolumn{6}{|l|}{ Highest level of education, combined households ( $n=590) \S \rrbracket$} \\
\hline Childhood household Adult household & & & & & \\
\hline$\geqslant 4$ y college & 219 & 131 & 1.00 & 1.00 & 1.00 \\
\hline$\geqslant 4$ y college & 87 & 135 & $1.04(0.65$ to 1.65$)$ & $1.15(0.72$ to 1.84$)$ & $1.14(0.70$ to 1.84$)$ \\
\hline$>4$ y college & 124 & 106 & $0.81(0.52$ to 1.26$)$ & $0.76(0.49$ to 1.19$)$ & $0.77(0.49$ to 1.20$)$ \\
\hline$<4$ y college $\quad \leqslant 4$ y college & 160 & 168 & $1.30(0.90$ to 1.86$)$ & $1.26(0.87$ to 1.81$)$ & $1.18(0.80$ to 1.73$)$ \\
\hline \multicolumn{6}{|l|}{ Occupation across lifecourse $(n=601)^{* *}$} \\
\hline Childhood household $\quad$ Adult household & & & & & \\
\hline Owner or supervisory & 262 & 123 & 1.00 & 1.00 & 1.00 \\
\hline Owner or supervisory & 89 & 204 & 1.68 (1.12 to 2.51$)$ & $1.71 \quad(1.14$ to 2.57$)$ & $1.52(1.00$ to 2.31$)$ \\
\hline Owner or supervisory & 122 & 143 & $1.18(0.79$ to 1.75$)$ & $1.12(0.75$ to 1.68$)$ & $1.01(0.67$ to 1.52$)$ \\
\hline Non-supervisory & 128 & 127 & $1.02(0.68$ to 1.54$)$ & $0.99(0.66$ to 1.49$)$ & $0.83(0.54$ to 1.27$)$ \\
\hline
\end{tabular}

* Model adjusted for age at baseline, age at menarche, parity, years of OC use, family history of early menopause. †Model additionally adjusted for race/ethnicity, smoking (never, past, and current), depression, and body mass index. ҒCalculated according to US Census Bureau 1998 Poverty Thresholds, by size of family and number of related children under 18 years. Poverty line defined as $\$ 16813$ for a family of four. §Highest educational level achieved by respondent's mother or father. $\mathrm{N}=13$ women could not recall parents' education. $\{$ Highest educational level achieved by respondent or respondent's most recent spouse/partner. ${ }^{*}$ Classified according to head of household.

the complementary log-log transform and assessing parallelism of the exposure-specific survival curves.

We evaluated the presence of statistical interaction by depression status by conducting subgroup analyses among depressed and non-depressed women at baseline. Because menstrual cycle definitions for perimenopause may misclassify obese premenopausal women as perimenopausal, we also conducted separate analyses among women with BMI $<25$ (normal BMI, according to WHO standards). As the majority of studies on socioeconomic position and onset of perimenopause have shown that adjustment for smoking dilutes the effect of socioeconomic position, we stratified analyses by smoking status (ever versus never) to examine whether our associations of interest were evident among never smokers.

Our outcome definition expanded on the classic definition of perimenopause by including women with changes in menstrual flow in addition to menstrual irregularity. ${ }^{28}$ Using the classic outcome definition (study definition criteria 1 and 3 only), we repeated all analyses to assess whether modifying our outcome definition would appreciably change our findings. Furthermore, to deal with our concern that initiation of hormone use over follow up may be related to the onset of perimenopausal symptoms and may differ by socioeconomic position, ${ }^{41}$ we conducted separate analyses ${ }^{92}$ in which we reclassified women as "perimenopausal" if they initiated any hormone use for "menstrual regulation or HRT" before, or in the same time interval as, the onset of perimenopausal symptoms $(n=33)$. As the latter analyses were similar to those using the original outcome definition, we present data only from the original analysis.

\section{RESULTS}

Table 1 provides data on selected baseline characteristics of our study cohort, stratified by lifetime economic distress. These data suggest that women reporting any economic distress $(n=203 ; 33.7 \%)$, especially in childhood and adulthood 
Table 4 Association between lifetime economic distress and onset of perimenopause, stratified by smoking status and body mass index at baseline, among 603 women from the Harvard Study of Moods and Cycles, Boston, Massachusetts, 1996-2000

\begin{tabular}{|c|c|c|c|c|c|}
\hline & \multirow[b]{2}{*}{$\begin{array}{l}\text { Total } \\
(n=603)\end{array}$} & \multicolumn{4}{|l|}{ All women } \\
\hline & & $\begin{array}{l}\text { Crude IR } \\
\text { (cases/1000 } \\
\text { woman years) }\end{array}$ & Crude IRR $(95 \% \mathrm{CI})$ & Adjusted IRR* (95\% CI) & Adjusted IRR† $(95 \% \mathrm{Cl})$ \\
\hline \multicolumn{6}{|c|}{ Never smokers $(n=330)$} \\
\hline \multicolumn{6}{|c|}{ Economic distress across lifecourse: } \\
\hline Never & 233 & 139 & 1.00 & 1.00 & 1.00 \\
\hline As child but not adult & 38 & 197 & 1.39 (0.78 to 2.47$)$ & 1.41 (0.79 to 2.54$)$ & 1.27 (0.69 to 2.32$)$ \\
\hline As adult but not child & 35 & 95 & 0.69 (0.33 to 1.43$)$ & 0.60 (0.29 to 1.28$)$ & 0.51 (0.24 to 1.09$)$ \\
\hline As both child and adult & 24 & 204 & 1.51 (0.80 to 2.86$)$ & 1.61 (0.84 to 3.11$)$ & $1.32(0.66$ to 2.66$)$ \\
\hline \multicolumn{6}{|c|}{ Ever smokers (n=273) } \\
\hline \multicolumn{6}{|c|}{ Economic distress across lifecourse: } \\
\hline Never & 167 & 111 & 1.00 & 1.00 & 1.00 \\
\hline As child but not adult & 35 & 103 & 0.93 (0.43 to 1.98 ) & $0.73(0.33$ to 1.60$)$ & 0.71 (0.31 to 1.63$)$ \\
\hline As adult but not child & 49 & 186 & 1.64 (0.95 to 2.87 ) & 1.55 (0.87 to 2.78$)$ & 1.39 (0.76 to 2.54$)$ \\
\hline As both child and adult & 22 & 238 & 2.12 (1.06 to 4.24$)$ & 2.01 (0.99 to 4.11$)$ & 1.86 (0.89 to 3.89 ) \\
\hline \multicolumn{6}{|c|}{ BMI $<25(n=406)$} \\
\hline \multicolumn{6}{|c|}{ Economic distress across lifecourse: } \\
\hline Never & 289 & 113 & 1.00 & 1.00 & 1.00 \\
\hline As child but not adult & 12 & 140 & 1.20 (0.65 to 2.22$)$ & 1.16 (0.62 to 2.16$)$ & 1.20 (0.64 to 2.25$)$ \\
\hline As adult but not child & 16 & 142 & $1.23(0.71$ to 2.11$)$ & $1.25(0.72$ to 2.16$)$ & 1.15 (0.66 to 2.02$)$ \\
\hline As both child and adult & 10 & 227 & 2.06 (1.06 to 3.99$)$ & $2.17(1.10$ to 4.29$)$ & 1.98 (0.99 to 3.97$)$ \\
\hline \multicolumn{6}{|c|}{ BMI 25+ (n=197) } \\
\hline \multicolumn{6}{|c|}{ Economic distress across lifecourse: } \\
\hline Never & 111 & 165 & 1.00 & 1.00 & 1.00 \\
\hline As child but not adult & 30 & 159 & 0.97 (0.48 to 1.95$)$ & 0.89 (0.43 to 1.84$)$ & 0.88 (0.41 to 1.86$)$ \\
\hline As adult but not child & 32 & 147 & 0.90 (0.45 to 1.80$)$ & 0.91 (0.44 to 1.88 ) & 0.78 (0.37 to 1.66$)$ \\
\hline As both child and adult & 24 & 212 & 1.30 (0.66 to 2.54$)$ & 1.27 (0.63 to 2.57$)$ & 1.04 (0.50 to 2.15$)$ \\
\hline
\end{tabular}

* Model adjusted for age at baseline, age at menarche, parity, years of oral contraceptive use, family history of early menopause. $†$ Model additionally adjusted for race/ethnicity, depression, and BMI (in smoking models) or smoking (in BMI models).

$(\mathrm{n}=46 ; 7.6 \%)$, were more likely to be current smokers, have a history of oral contraceptive use, report marital disruption, have a higher mean body mass index, and be diagnosed with major depression.

A total of 177 women $(29.4 \%)$ reached our outcome definition for perimenopause over 36 months of observation. The overall median age at onset of perimenopause was 45.7 years (95\%CI 45.5 to 46.9) (data not shown). Over the course of follow up, $109(61.6 \%)$ women reported changes in menstrual cycle length, 100 (56.5\%) reported changes in menstrual flow or duration, and $13(7.3 \%)$ reported amenorrhea for more than three months. Sixty nine $(39.0 \%)$ women experienced a change in cycle length only, 61 (34.5\%) women experienced change in menstrual flow or duration only, four $(2.3 \%)$ women experienced amenorrhea only, and 43 (24.2\%) women reported more than one perimenopausal event. In terms of the timing of events, $84(47.5 \%)$ women reported a change in cycle length as their first event, $80(45.2 \%)$ reported a change in menstrual flow or duration as their first event, and four $(2.3 \%)$ reported amenorrhea as their first event; nine (5.0\%) women experienced two or more events in the same time interval.

Table 2 provides information on selected demographic and reproductive characteristics, providing absolute incidence rates for women who reached perimenopause for each stratum of interest. As expected, Cox proportional hazards models for the full dataset indicated that age was the strongest univariate predictor of perimenopause over the study period: with each one year increment of age, incidence of perimenopause increased linearly by $13 \%$ (95\%CI 1.07 to 1.21 ). At any given age, increased rates of entry into perimenopause were also shown for women who were current cigarette smokers, lived with a smoker for more than five years, had a BMI $>30$ (obese according to WHO standards), self identified as women of colour, reported a family history of early natural menopause, and met DSM-IV criteria for major depression.

Table 3 provides data on childhood and adult measures of socioeconomic position, along with crude and adjusted incidence rate ratios for entry into perimenopause. Compared with women reporting no lifetime economic distress, women reporting both childhood and adult economic distress entered perimenopause 1.2 years earlier (median age: $45.9 \vee 44.7$ years). Median age at perimenopause was 45.3 years for women reporting economic distress as a child only and 45.7 years for women reporting economic distress as an adult only (data not shown). Unadjusted incidence rates of perimenopause were $75 \%$ higher among women reporting both childhood and adult economic distress relative to women reporting no lifetime economic distress. After adjusting for age at baseline, age at menarche, parity, oral contraceptive use, and family history of early menopause, the association remained similar in magnitude. However, after adjustment for potential intermediary factors such as smoking and BMI, the overall strength of the association weakened and the 95\% confidence interval included one. Variables representing economic distress in childhood only or adulthood only were equally weakly associated with perimenopause. When we considered any experience as a child or as an adult, childhood experience of economic distress was more strongly associated with perimenopause (childhood HR $=1.35,95 \%$ CI 0.96 to $1.90 v$ adulthood HR=1.27, 95\%CI 0.91 to 1.77) (data not shown).

Inverse associations were also evident for childhood and current adult household education measures. When comparing the lowest with the highest level of educational attainment, increases in risk of perimenopause ranged from $50 \%$ to $73 \%$. Combined household education was only weakly associated with perimenopause when comparing low with high educational attainment across the lifespan ( $\mathrm{HR}=1.19$, 95\%CI 0.81 to 1.75 ); however, among women with low childhood household education, remaining in an adult household with low educational attainment was associated with $60 \%$ increased risk of perimenopause (95\%CI 0.96 to 2.45). Among women with a head of household classified as "owner or supervisory" in childhood, we observed a positive association when comparing "non-supervisory" to "owner or supervisory" occupation in adulthood ( $\mathrm{HR}=1.53,95 \% \mathrm{CI} 1.01$ to 2.33 ). 
None of our three current measures of household income was associated with risk of perimenopause.

Stratified analyses (table 4) by smoking status at baseline suggested some increase in risk among never smokers for childhood and lifecourse measures of economic distress. Among ever smokers, stronger positive associations were observed for adult and lifecourse economic distress. Among women with a $\mathrm{BMI}<25$, childhood and adulthood economic distress was associated with a twofold increased risk of perimenopause compared with no lifetime economic distress (95\%CI 0.99 to 3.97). In contrast, among women with a BMI 25 or greater, null associations were observed for childhood and adulthood stages of exposure whether considered individually or combined. No statistical interaction was evident between a history of depression at baseline and any measures of socioeconomic position with respect to perimenopause.

When we reclassified women who started hormone use before the report of a perimenopausal criterion $(n=33)$, our results did not change appreciably. Median age at perimenopause was 45.5 years for the whole cohort of women, 44.0 years for women reporting both childhood and adulthood economic distress, 44.5 years for economic distress as a child only and adult only, respectively, and 45.5 years for women reporting no economic distress across the lifecourse. The association for women reporting both childhood and adulthood economic distress was slightly stronger than previously found (fully adjusted HR=1.56, 95\%CI 0.99 to 2.47). Associations with household education were slightly weaker, but in the same direction as before, while associations for current household income remained null.

Analyses in which we used the classic definition of perimenopause yielded similar findings compared with our expanded outcome definition $(n=116$ cases $)$, and all associations were in the same general direction. Median age at perimenopause was 48 years for the whole cohort and 45.5 years for women reporting both childhood and adulthood economic distress. Median age estimates could not be computed for women reporting no lifetime economic distress because less than $50 \%$ of this subgroup reached the classic definition of perimenopause. Childhood economic distress became more strongly associated with perimenopause (fully adjusted $\mathrm{HR}=1.27,95 \% \mathrm{CI} 0.71$ to 2.28 ) while combined childhood and adulthood exposure weakened (fully adjusted $\mathrm{HR}=1.33$, $95 \%$ CI 0.70 to 2.52 ). Individual education variables remained inversely associated with perimenopause, even more so for childhood household education (comparing lowest with highest level, $\mathrm{HR}=1.76,95 \% \mathrm{CI} 0.83$ to 3.73 ), respondent education ( $\mathrm{HR}=1.55,95 \% \mathrm{CI} 0.74$ to 3.24$)$, and current adult household education ( $\mathrm{HR}=1.99,95 \% \mathrm{CI} 0.78$ to 5.11 ). Overall, previous associations between socioeconomic position and perimenopause remained in the same direction and current measures of household income revealed no association with outcome.

\section{DISCUSSION}

This study found that women reporting both childhood and adult economic distress had increased rates of entry into perimenopause compared with women reporting no economic distress across the lifecourse, after adjustment for potential confounders. Further adjustment for smoking and BMI, probable intermediates of this association, attenuated our estimates of effect but did not appreciably change our overall findings. Despite limited numbers of never smokers who experienced economic distress, our results suggest that socioeconomic position and onset of perimenopause might be associated in a non-smoking population of women. A larger population of non-smokers with greater heterogeneity in socioeconomic position would be better suited for testing this hypothesis. All of our measures of educational attainment were inversely associated with perimenopause, with the

\section{Key points}

- Existing research has yielded inconsistent findings on the relation between adult social class and perimenopause.

- Despite growing recognition of the combined impact of childhood and adult socioeconomic position on risk of cardiovascular disease and all cause mortality, little research has investigated their influence on ovarian function.

- In a prospective cohort study of late reproductive aged women from Boston, Massachusetts, we observed higher rates of entry into perimenopause among women reporting economic distress across the lifecourse and low educational attainment.

- No additional current measures of socioeconomic position were associated with early inception of perimenopause.

- Studies investigating factors related to the perimenopausal transition might consider taking into account socioeconomic position across the life span.

exception of combined household education, which showed no evidence of a lifetime effect. None of our current measures of household income-as measured by current financial stability, poverty status, or income from assets-revealed any association with onset of perimenopause.

Our study findings might have been affected by selection bias, measurement error, and confounding. In cohort studies, non-response bias is invariably a potential source of error. Among the 907 active cohort members initially sent the cross sectional survey, $733(81 \%)$ women responded with usable information. However, there were no appreciable differences in length of follow up or time to perimenopause comparing women who did and did not complete the Survey of Interpersonal Relations. Among women who completed the survey, application of our eligibility criteria resulted in the exclusion of 130 women because of hormone use at baseline, irregular cycling, or left censoring (that is, women who were perimenopausal prior to the baseline interview). These women were more likely to be younger, use oral contraceptives, have a lower BMI, and be nulliparous. However, almost all of these associations could be explained by the differential age distributions of women included compared with excluded from the study, an imbalance that is not directly related to socioeconomic position or any of its correlates.

Another form of selection bias may have been introduced by differential loss to follow up or informative censoring (that is, censoring that is related to exposure and underlying disease status). Among women who were included in the analysis, a total of 59 women dropped out of the study and an additional 64 women were censored (because of pregnancy, hormone use, or surgical/medical menopause) before the end of the study period. Compared with women who remained in the study, early drop outs were more likely to have a higher mean age at baseline ( 40.6 years $v 40.1$ years) and be diagnosed with major depressive disorder. However, women reporting any economic distress were no more likely to drop out than women not reporting economic distress: mean follow up times were 35.2 months for women reporting any economic distress and 35.1 months for women reporting no lifetime economic distress. As losses were largely unrelated to the exposure of interest, selection bias is an unlikely explanation of our findings.

Misclassification of exposure is a potential concern because socioeconomic position is a complex construct and information on social conditions in childhood was based on recall in adulthood. Mitigating these concerns, our study used a 
range of previously validated individual and household level measures of socioeconomic position that assessed income, wealth, material deprivation, and educational level. ${ }^{22} 2325$ Recall of childhood socioeconomic position-on the basis of occupational social class of the head of the household and father's education-has been shown to be reliable among a comparable population of US women and in research conducted in the United Kingdom. ${ }^{24}{ }^{43}$ Furthermore, measures of economic distress used in the present study have been shown to have good correlation with each other. ${ }^{23}$ Thus, error in the measurement of socioeconomic position is unlikely to have seriously biased our results. It is possible, however, that our effect estimates for socioeconomic position may have been attenuated because of the relatively homogenous composition of the study population with respect to education, income, and other measures of current economic wellbeing.

With regard to classification of outcome, results of our study may have been weakened by imprecise measurement of perimenopause and by the age range of the study population. In the longitudinal Massachussetts Women's Health Study, the classic definition of perimenopause was defined as self reported menstrual cycle irregularity. ${ }^{13} 32$ We expanded this classic definition of perimenopause to include changes in amount and duration of menstrual flow in light of recent research by Mitchell et al, ${ }^{28}$ demonstrating that changes in menstrual flow often accompany cycle irregularity. By increasing the sensitivity of our outcome definition relative to the classic definition, we may have misclassified some premenopausal women as perimenopausal. However, when we used the classic definition only ( $\mathrm{n}=116$ cases), our results did not differ appreciably from the main study results.

Our power to detect associations may have been reduced by the baseline age of the cohort. Although perimenopausal changes can occur as early as age $36,{ }^{28-30}$ menstrual changes are most likely to occur during ages $40-44$ years, ${ }^{28}$ suggesting that younger women may have been censored because of study completion before reaching the age range at which perimenopause typically occurs. Therefore our study findings may best be interpreted as lifetime socioeconomic factors in relation to early onset of perimenopause.

As about $10 \%$ of women do not experience menstrual changes suggestive of perimenopause, ${ }^{12}$ we may not have identified all women who entered perimenopause during the study's duration. The alternative strategy of analysing menstrually timed hormone profiles suffers from methodological problems, such as high variability in follicle stimulating hormone levels between measurement intervals, even when measured in the early follicular phase. For this reason, several studies have suggested that follicle stimulating hormone as a single measure may not be a reliable indicator of perimenopause. ${ }^{44-46}$ These methodological challenges have prompted epidemiologists to rely increasingly on women's self reported changes in menstrual cycles. ${ }^{31}$ Validation of the definition used in this study requires longitudinal data demonstrating close correlation between menstrual cycle markers and known hormonal changes that accompany perimenopause. Efforts to validate menstrual measures of perimenopausal status are currently underway. ${ }^{32} 46-48$

Our study involved prospective assessment of perimenopause, an approach less prone to recall bias than retrospective assessments commonly found in non-longitudinal epidemiological studies. Whereas other studies on perimenopause have used daily menstrual diaries to record menstrual changes, ${ }^{13}$ our study required women to recall the occurrence of any menstrual irregularity in the previous six month interval at in-person interviews every six months. It is possible that the occurrence of menstrual irregularity was not as accurately recalled in our study as it would have been given the daily monitoring of menstrual events. However, we do not believe reporting errors would differ by any indicators of socioeconomic position. If misclassification of perimenopause is unre- lated to socioeconomic position or any correlates of socioeconomic positions, then such misclassification is likely to be non-differential and bias our findings towards the null. If misclassification is differential, the direction of bias may be in either direction. For example, if highly educated women were more likely than less educated women to accurately recall menstrual changes, we would expect even stronger associations with perimenopause than those actually observed in this study. As participants were unaware of the study hypothesis and had already completed several follow up visits by the time of the survey mailing, the degree of reporting bias is likely to be small.

Keeping in mind these caveats, it is useful to compare our findings to those of previous studies on associations between socioeconomic position and the menopausal transition. Of the few studies examining this relation, ${ }^{2-9}$ most have reported either no association between early ovarian decline and socioeconomic position (as measured by occupational or social class, education, household income, marital status, or location of residence) or else have attenuated associations by adjusting for smoking and BMI. ${ }^{6-9}$ Most of these studies, however, have measured only the effect of adult socioeconomic position. ${ }^{2-46}$ Only two prospective cohort studies measured both childhood and current socioeconomic position, using data on education and occupational class. One prospective cohort study ${ }^{9}$ found no association between socioeconomic status at any time period and age at perimenopause either before or after adjustment for smoking (never, past, and current) and BMI. Another prospective cohort study ${ }^{7}$ found strong univariate associations between early age at menopause and low social class as both a child and an adult, yet after adjustment for smoking, current $\mathrm{BMI}, \mathrm{FEV}_{1}$, insulin, and uric acid levels, these associations were attenuated. ${ }^{7}$ Neither of these studies created a cumulative measure of socioeconomic position that took into account childhood and adulthood position combined.

Adding credence to our results, associations with perimenopause found in our study were similar to those found in other studies with respect to age at menarche, ${ }^{46}$ parity, ${ }^{46}$ and oral contraceptive use use. ${ }^{12}{ }^{46}$ As suggested in one other study, ${ }^{46}$ the increased IRR for obese women (BMI>30) may merely reflect misclassification of premenopausal women as perimenopausal, as obese women are more likely to experience menstrual cycle irregularity. After restricting our sample to normal weight women $(\mathrm{BMI}<25)$, our associations for lifetime socioeconomic position were unchanged or slightly stronger than those observed in our overall analyses. Several studies have suggested that risk of early menopause is higher in current smokers than in ex-smokers and never smokers, and that current smoking may advance menopause by about 1.3 years. ${ }^{2-11}$ Associations between cigarette smoking and onset of perimenopause in our study population were consistent with previous studies. ${ }^{10}{ }^{11}$ Our study also showed evidence of an effect of exposure to second hand smoke in the home, an unexplored factor in previous research. As smokers have been found to have a shorter perimenopausal transition than nonsmokers, ${ }^{13}$ the effect of smoking on age at menopause may be expected to be stronger than its effect on age at perimenopause. ${ }^{9}$ These data support the predominant theory that smoking has a direct toxic effect on oocytes and may accelerate the rate of follicular atresia. ${ }^{17}$ However, it remains unclear as to why former smokers have a risk of menopause that is similar to never smokers.

A woman's pool of ovarian follicles becomes fixed early in life. At 20 weeks gestation, she will receive her maximum endowment of primordial follicles (6-7 million); by birth, this number will drop to approximately 400000 and thereafter decline until only a relatively few, poorly responsive follicles remain at the time of menopause. ${ }^{49}$ Follicular atresia by apoptosis occurs throughout a woman's life. Relative to atresia, ovulation accounts for only a small proportion of depleted follicles during a woman's lifetime. ${ }^{46-50}$ Mechanisms 
by which lifetime socioeconomic position could influence early decline in ovarian function are through exposures that affect either the initial number of oocytes in utero or the rate at which oocytes are depleted over the lifecourse. Studies have shown that stressful life events, ${ }^{81}$ undernourishment, ${ }^{52}$ and increased exposure to environmental toxins (for example, tobacco and lead), ${ }^{10534}$ are associated with an earlier menopause. Moreover, the "life history" theory of ovarian aging suggests that factors such as maternal smoking and poor fetal growth may lead to an earlier menopause by reducing the number of primordial follicles in utero. ${ }^{556}$ All of the above factors may be markers for adverse socioeconomic conditions across the life span.

Investigation of perimenopause has important implications for women's health. Our findings suggest that it may not be sufficient to measure socioeconomic position at only one point in time, whether it be in utero, childhood, or adulthood; rather, measures taken at each and all of these times may matter. Lending support to the idea that lifetime socioeconomic position may be an important determinant of onset of perimenopause, our study suggests that cumulative or lifetime socioeconomic position may influence ovarian function more strongly than either childhood or adult socioeconomic position alone. Similar findings have been observed in other studies investigating heart disease and mortality in relation to socioeconomic position, leading some health researchers to argue that risk of disease in later life may begin as early as in utero. ${ }^{57}$ Future research might investigate whether there are critical time windows during which exposure to stress and environmental toxins, including exposure to first hand and second hand smoke, have the greatest impact. Additional research might also investigate whether our findings can be replicated in other populations, including those with more racial/ethnic and socioeconomic heterogeneity.

\section{Authors' affiliations}

L A Wise, B L Harlow, Obstetrics and Gynecology Epidemiology Center, Brigham and Women's Hospital/Harvard Medical School, Boston, USA

N Krieger, Department of Health and Social Behavior, Harvard School of Public Health, Boston, USA

S Zierler, Department of Community Health, Brown University School of Medicine, Providence, USA

L A Wise, Department of Epidemiology, Harvard School of Public Health

Funding: this research was funded by the National Institute of Mental Health, Grants RO1-MH577351 and RO1-MH50013.

Conflicts of interest: none.

\section{REFERENCES}

1 Kuh D, Ben-Shlomo Y, eds. A lifecourse approach to chronic disease epidemiology: tracing the origins of ill health from early to adult life. Oxford University Press: Oxford, 1997

2 McKinlay SM, Bifano NL, McKinlay JB. Smoking and age at menopause in women. Ann Intern Med 1985;103:350-6.

3 Stanford JL, Hartge $\mathrm{P}$, Brinton LA, et al. Factors influencing the age at natural menopause. J Chronic Dis 1987;40:995-1002

4 Luoto R, Kaprio J, Uutela A. Age at natural menopause and sociodemographic status in Finland. Am J Epidemiol 1994;139:64-76.

5 Gold EB, Bromberger J, Crawford S, et al. Factors associated with age at natural menopause in a multiethnic sample of midlife women. $\mathrm{Am} \mathrm{J}$ Epidemiol 2001;153:865-74

6 Brambilla DJ, McKinlay SM. A prospective study of factors affecting age at menopause. J Clin Epidemiol 1989;42:1031-9.

7 Nilsson P, Moller L, Koster A, et al. Social and biological of early menopause: a model for premature aging. J Intern Med 1997;242:299-305

8 Bromberger IT, Matthews KA, Kuller LH, et al. Prospective study of the determinants of age at menopause. Am J Epidemiol 1997:145:124-33.

9 Hardy R, Kuh D, Wadsworth M. Smoking, body mass index, socioeconomic status and the menopausal transition in a British national cohort. Int J Epidemiol 2000;29:845-51.

10 Jick H, Porter J, Morrison AS. Relation between smoking and age of natural menopause. Lancet 1977;i:1354-5.

11 Willett W, Stampfer M, Bain C, et al. Cigarette smoking, relative weight, and menopause. Am J Epidemiol 1983;117:651-8.
12 Hardy R, Kuh D. Reproductive characteristics and the age at inception of the perimenopause in a British national cohort. Am J Epidemiol 1999; 149: 612-20

13 McKinlay SM, Brambilla DJ, Posner JG. The normal menopause transition. Maturitas 1992;14:103-5.

14 Matthews KA, Meilahn E, Kuller LH, et al. Menopause and risk factors for coronary heart disease. N Engl J Med 1989;321:641-6.

15 Kritz-Silverstein D, Barrett-Connor E. Early menopause, number of reproductive years, and bone mineral density in postmenopausal women. Am J Public Health 1993;83:983-8.

16 Frackiewicz EJ, Cutler NR. Women's health care during the perimenopause. J Am Pharm Assoc 2000;40:800-11.

17 Cramer DW, Xu H, Harlow BL. Does "incessant" ovulation increase risk for early menopause? Am J Obstet Gynecol 1995; 172:568-73.

18 Whelan EA, Sandler DP, McConnaughey DR, et al. Menstrual and reproductive characteristics and age at natural menopause. Am J Epidemiol 1990;131:625-32.

19 Radloff LS. The CES-D Scale: A self-report depression scale for research in the general population. Appl Psychol Measurement 1977;1:385-401

20 Spitzer RL, Williams JB, Gibbon M, et al. The structured clinical interview for DSM-III-R (SCID): I: history, rationale, and description. Arch Gen Psychiatry 1992;49:624-9.

21 Harlow BL, Cohen LS, Otto MW, et al. Demographic, family, and occupational characteristics associated with major depression: The Harvard Study of Moods and Cycles. Acta Psychiatr Scand 2002; 105:209-17.

22 Krieger N, Chen JT. Sociodemographic and cultural module for the Breast Cancer Core Questionnaire Project. Prepared for the Breast Cancer Core Questionnaire Project, National Institutes of Health and National Action Plan on Breast Cancer. Bethesda, MD: September 1996.

23 Krieger N, Williams DR, Moss NE. Measuring social class in US public health research: Concepts, methodologies, and guidelines. Ann Rev Public Health 1997; 18:341-78.

24 Krieger N, Okamoto A, Selby JV. Adult female twins' recall of childhood social class and father's education: A validation study for public health research. Am J Epidemiol 1998;147:704-8.

25 Krieger N, Chen JT, Selby JV. Comparing individual-based and household-based measures of social class to assess inequalities in women's health: a methodological study of 684 US women. J Epidemiol Community Health 1999;53:612-23.

26 US Census Bureau. Current Population Reports, Series P60-207. Poverty in the United States: 1998. Washington, DC: US Government Printing Office, 1999. (http://www.census.gov/hhes/poverty/threshld/ thresh98.html).

27 World Health Organisation Scientific Group. Research on the menopause. WHO Technical Services Report Series 670. Geneva: WHO, 1981.

28 Mitchell ES, Woods NF, Mariella A. Three stages of the menopausal transition from the Seattle Women's Health Study: toward a more precise definition. Menopause 2000;7:334-49.

29 Treloar AE. Menstrual cyclicity and the pre-menopause. Maturitas 1981;249:3.

30 Treloar AE. Menarche, menopause and intervening fecundability. Hum Biol 1974;46:89-107.

31 Brambilla DJ, McKinlay SM, Johannes CB. Defining the perimenopause for application in epidemiologic investigations. Am J Epidemiol 1994:140:1091-5.

32 Avis NE, McKinlay SM. The Massachusetts Women's Health Study: an epidemiologic investigation of the menopause. JAMWA 1995;50:45-9 63.

33 Dennerstein L, Dudley EC, Hopper JL, et al. A prospective population-based study of menopausal symptoms. Obstet Gynecol 2000;96:351-8

34 World Health Organisation. Physical status: the use and interpretation of anthropometry. Geneva: WHO, 1995

35 Kaplan EL, Meier P. Nonparametric estimation from incomplete observations. J Am Stat Assoc 1958;53:457-81.

36 Mantel N. Evaluation of survival data and two new rank order statistics arising in its consideration. Cancer Chemother Rep 1966;50:163-70.

37 Cox DR. Regression model and life tables (with discussion). J R Stat Soc (B) 1972;34:187-220.

38 Greenland S, Finkle WD. A critical look at methods for handling missing covariates in epidemiologic regression analyses. Am J Epidemio $1995 ; 142: 1255-64$.

39 SAS Institute. SAS for Windows Release 8.0. Cary, NC: SAS Institute, 2000.

40 Allison PD. Survival Analysis using the SAS System: a practical guide. Cary, NC: SAS Institute, 1995

41 Marks NF, Shinberg DS. Socioeconomic status differences in hormone therapy. Am J Epidemiol 1998;148:581-93.

42 Prentice RL, Kalbfleisch JD, Peterson AV, et al. The analysis of failure times in the presence of competing risks. Biometrics 1978;34:541-54

43 Berney LR, Blane DB. Collecting retrospective data: accuracy of recall after 50 years judged against historical records. Soc Sci Med 1997:45:1519-25.

44 Burger HG, Dudley EC, Hopper JL, et al. The endocrinology of the menopausal transition : a cross-sectional study of a population-based sample. J Clin Endocrinol Metab 1995;80:3537-45.

45 Metcalf MG. The approach of menopause: A New Zealand Study. NZ Med J 1988;101:103-6.

46 Cooper GS, Baird DD, Darden FR. Measures of menopausal status in relation to demographic, reproductive, and behavioral characteristics in 
a population-based study of women aged 35-49 years. Am J Epidemiol 2001;153:1159-65.

47 Sowers MF, Crawford S, Sternfeld B, et al. Design, survey sampling and recruitment methods of SWAN: a multi-center, multi-ethnic,

community-based cohort study of women and the menopausal transition. In: Wren J, Lobo RA, Kelsey J, et al, eds. Menopause: biology and pathobiology. New York: Academic Press, 2000.

48 Hunter $\boldsymbol{M}$. The South-East England longitudinal study of the climacteric and postmenopause. Maturitas 1992;14:117-26.

49 McGee EA, Hsueh AJW. Initial and cyclic recruitment of ovarian follicles. Endocrine reviews 2000;21:200-14.

50 Klein NA, Soules MR. Endocrine changes of the perimenopause. Clin Obstet Gynecol 1998:41:912-20.

51 Berga SL. How stress can affect ovarian function. Contemp Obstet Gynecol 1993;Jul:87-94
52 Torgerson JJ, Avenell A, Russell IT, et al. Factors associated with onset of menopause in women aged 45-49. Maturitas 1994;19:83.

53 Junaid $M$, Chowdhuri DK, Narayan R, et al. Lead-induced changes in ovarian follicular development and maturation in mice. J Toxicol Environ Health 1997;50:31-40.

54 Mahaffey KR, Annest JL, Roberts J, et al. National estimates of blood lead levels: United States, 1976-1980: Association with selected demographic and socioeconomic factors. N Engl J Med 1982:307:573-9

55 Kuh DL, Wadsworth M, Hardy R. Women's health in midlife: the influence of the menopause, social factors and health in earlier life. $\mathrm{Br} J$ Obstet Gynaecol 1997; 104:923-33.

56 Sowers MFR. The menopause transition and the aging process: a population perspective. Aging Clin Exp Res 2000;1 2:85-92.

57 Cresswell JL, Egger P, Fall CHD, et al. Is the age of menopause determined in-utero? Early Hum Dev 1997;49:143-8.

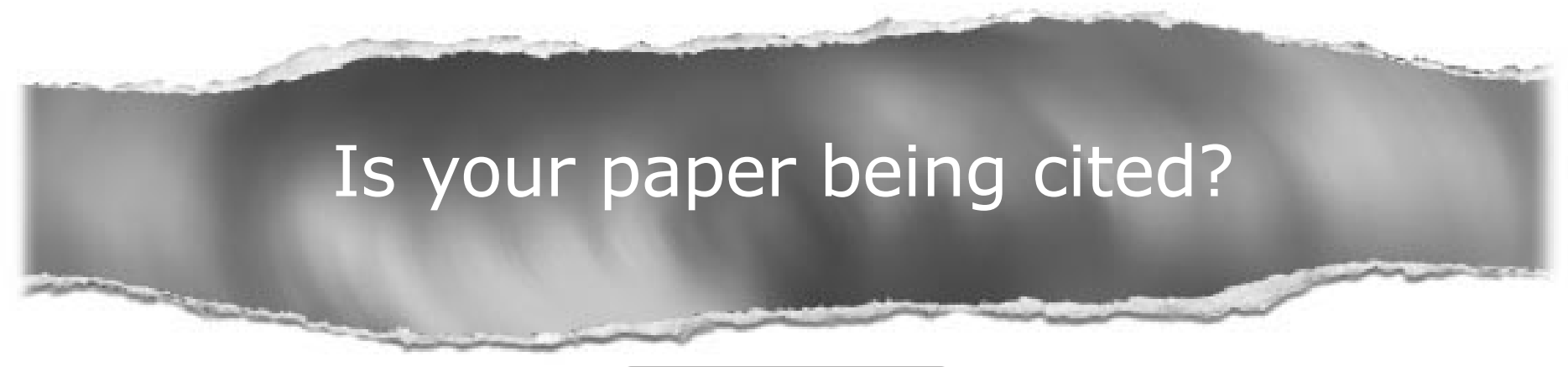

\section{CiteTrack service}

CiteTrack will alert you by email whenever new content in the Journal of Epidemiology and Community Health or a participating journal is published that matches criteria you want to track Topics: Tell CiteTrack which words or subjects to watch for in new content Authors: Be alerted whenever key authors you are following publish a new paper Articles: Know whenever a paper of interest to you is referenced by another paper

www.jech.com 